\title{
"TUDO ARDE, TUDO QUEIMA": O SINCRETISMO DE GEMMA FERRUGGIA ENTRE A VIAGEM ENTRE A VIAGEM REAL E A VIAGEM LITERÁRIA
}

Karine Simoni ${ }^{1}$

1-Universidade Federal de Santa Catarina, Florianópolis, Santa Catarina, Brasil

Desde os primórdios da presença europeia no território hoje mapeado como Amazônia, as paisagens cobertas por florestas tropicais, campos, igapós, rios e lagoas, e a presença de contingentes humanos de culturas até então nunca vistas, têm provocado estupor e fascínio, que nutriram e nutrem a ambição e o desejo de aventureiros e exploradores em conhecer e apossar-se do lugar. Atraídos por esse cenário, indivíduos de diferentes nacionalidades e com variados objetivos dirigiram-se para a região ao longo dos séculos, e muitos deles dedicaram-se à narrativa escrita de suas experiências, imaginações e expectativas de viagem.

A presença de mulheres no espaço da viagem e da sua escrita foi no geral rara; mesmo com os avanços das lutas feministas que se intensificaram a partir do século XIX, a mulher, grosso modo, até aquele período permaneceu confinada ao espaço doméstico e à imagem de esposa e mãe, de modo que as mulheres que se destacaram como viajantes-escritoras foram as que predispunham de certo grau de instrução e de uma posição social que thes possibilitaram sair da imobilidade e participar de uma viagem. É o caso de Gemma Ferruggia, que esteve no Brasil em dois momentos: em 1898 e em 1921, sempre junto com seu marido, e que, a respeito da primeira viagem, escreveu o relato Nostra Signora del mar dolce. Missioni e paesaggi dell'Amazzonia, publicado em Milão em 1902, no qual relata, analisa e (re)cria suas 
impressões das experiências vividas, e do qual aqui é apresentado e traduzido o capítulo VI, intitulado Madonna Fantasia.

Nascida em 1867 em Livorno, cidade portuária da Toscana, Itália, e falecida em Milão em 1930, Ferruggia participou de modo bastante ativo das discussões políticas do seu tempo, em especial no campo do feminismo, da imigração e do nacionalismo. Seus posicionamentos transparecem nos textos literários e ensaísticos que escreveu e constituem, de alguma maneira, o modus operandi das suas memórias, análises e escrituras, inclusive no seu relato de viagem, e, portanto, não devem ser negligenciados por quem a traduz.

Romancista, jornalista, conferencista, dramaturga e ensaísta, embora hoje Ferruggia seja ignorada pelas histórias literárias e pela crítica ${ }^{1}$, escreveu os romances Verso il nulla (1890, premiado em 1894), L'idea (1891), L'enigma soave (1892) e Follie muliebri (1893), todos bem recebidos pela crítica e o último traduzido para o inglês; a novela Odi et amo (1899), composta após uma estadia em Paris; uma série de artigos para os jornais La Tribuna, Corriere della sera, La Stampa, La Donna, tendo ainda atuado como correspondente de guerra durante a Primeira Guerra para o jornal Il fronte interno. No campo do teatro compôs o monólogo Come allora!, o drama Amata Desclée, uma homenagem à atriz francesa, e La gioia di vivere (1907), com o qual finalmente foi reconhecida nessa área. Como ensaísta destaca-se Il cervello della donna: intellettualità femminile (1900), em que dá visibilidade à atividade intelectual das mulheres ao longo da história. ${ }^{2}$ É esse, aliás, o fio condutor da obra de Ferruggia, que desde o primeiro romance manifestou seu pensamento sobre a questão feminista, que foi constantemente revisto e desenvolvido nos escritos e nas conferências posteriores. Boa parte da sua obra teve o objetivo de analisar a presença das mulheres na literatura italiana e de reunir os triunfos, as dores e as humilhações vividas por elas.

\footnotetext{
${ }^{1}$ Como exceção, destaco os estudos de Marzia Lea Pacella (1997), César Palma dos Santos (2014) e Chiara Evangelista (2016).

${ }^{2}$ As informações biobibliográficas foram extraídas de Lea Pacella (1997).
}

Cad. Trad., Florianópolis, v. 41, n $^{0}$ esp. 1, p. 273-287, jan/jul, 2021. 
As posições de Ferruggia perante as demandas dos movimentos feministas, porém, foram motivo de controvérsia e por isso criticadas, a ponto de ser definida como antifeminista. Isso porque defendia que, embora à mulher não devesse ser delegado um lugar de submissão, tampouco deveria ser-lhe dado um papel social igual ao do homem. Segundo Lea Pacella (1997), Ferruggia retratou analogias e diferenças entre escritores e escritoras, mas absteve-se de refletir sobre conceitos de inferioridade e superioridade; criticou as associações e as manifestações públicas das mulheres e defendeu a ação individual e a educação como motor das esperadas mudanças sociais. Essas ideias não estão apenas nos textos ficcionais e ensaísticos, como também no seu relato de viagem: ao comentar as leis de Jurupari sobre as mulheres, e que davam a elas uma condição de submissão ao homem, ela afirma que essas normas "em grande parte, deveriam ser seguidas pelas mulheres de todos os países, diga-se sem maldade. ${ }^{3 "}$ (186)

A defesa dos movimentos nacionalistas é outra característica de Ferruggia, o que pode ser aferido em especial pela constatação da sua amizade e admiração pelo poeta e romancista Gabriele D'Annunzio, grande incentivador do nacionalismo na Itália; admiração esta que se reflete também no texto aqui traduzido, seja através de citações diretas do autor, seja no partilhamento de suas ideias.

Para melhor traduzir a narrativa de viagem aqui apresentada, foi preciso considerar tais aspectos da visão de mundo da autora, pois, como procurarei mostrar, não estão dissociados da sua maneira de enxergar os locais visitados, de lembrá-los e descrevê-los. Essa é, de fato, uma das teses de César Palma dos Santos, que em seu trabalho de doutorado "Nostra Signora del Mar Dolce: A (re) criação da viagem na narrativa de Gemma Ferruggia” (2014), observa que a narrativa de Ferruggia é resultado de um trabalho que mescla realidade e ficção, num trabalho da memória, pois,

${ }^{3}$ Norme che, in gran parte, dovrebbero esser seguite dalle donne di ogni paese: sia detto senza cattiveria. Essa e todas as traduções citadas são de minha autoria.

Cad. Trad., Florianópolis, v. 41, n $^{0}$ esp. 1, p. 273-287, jan/jul, 2021. 
levando-se em conta a experiência da viajante como alguém que já havia produzido quatro romances e, portanto, era criadora de ficção, percebe-se que a narração dos episódios não se dá de forma simples e que na sua construção a autora serviu-se de suas habilidades ficcionais. (Santos, 233)

e, acrescento, com o propósito de defender suas posições políticas. A esse respeito, a própria autora afirma no seu relato: "A imaginação dos velhos é, sem dúvida, a memória; agora, algumas vezes, parece que os jovens estão fazendo quase um compilado ideal para aquela distante fantasia." ${ }^{4}$ (83)

Em relação à estrutura, as 417 páginas do texto estão divididas em nove capítulos, duas dedicatórias, uma carta e um apêndice. As dedicatórias são endereçadas ao governador do Pará, Paes de Carvalho, e ao marquês Carlo Ermes Visconti di San Vito, personalidades de influência política nos contextos brasileiro e italiano. A carta - um elogio da obra - é assinada pelo filósofo italiano Augusto Conti (1822-1905) para quem, de acordo com uma nota dos editores, Ferruggia teria enviado os originais. Tais elementos são indícios do círculo político e intelectual do qual a autora fazia parte. Os capítulos são assim intitulados: I. Un dolore e una chimera; II. Belem; III. Foreste e colonie; IV. Jambù-Assù e l'Aldeia; V. Aura Mistica; VI. Madonna Fantasia; VII. L'isola de Marajò e Marapanin; VIII. Lungo il solenne fiume; IX. Manaos. Cada capítulo dispõe de um incipit no qual estão dispostos os assuntos que serão discorridos, de modo que servem como um resumo-guia para o público leitor. O Apêndice trata de considerações acerca da notícia de um confronto entre índios e missionários capuchinhos no Maranhão, que Ferruggia teria conhecido e que teriam sido mortos pelos índios enquanto ela terminava de escrever o capítulo $\mathrm{V}$.

Alguns dos assuntos tratados por Ferruggia são: motivações e preparativos da viagem, travessia do Atlântico, primeiras impres-

${ }^{4}$ L'immaginazione dei vecchi è, sensa dubbio, la memoria: ora, qualche volta, pare ai giovani di far quase um ideale raccolto per quella lontana fantasia.

Cad. Trad., Florianópolis, v. 41, $\mathrm{n}^{0}$ esp. 1, p. 273-287, jan/jul, 2021.276 
sões, angústia com a febre amarela que acometera o marido, visões da exuberante floresta, contatos com autoridades e imigrantes, hospitalidade e hábitos culinários dos habitantes da região, lendas e costumes indígenas, africanos e portugueses, relatos sobre a economia e sobre acontecimentos da história do Brasil, festas populares, encontro com missionários católicos, dificuldades de transporte, falta de conforto e de higiene, visita ao Teatro de Manaus, e, por fim, a crise nervosa que a fez trancar-se num hotel por alguns dias, até que seu marido optasse por acatar o pedido de interromper a viagem e o casal retorna à Europa. Os capítulos V e VI, dedicados à religiosidade e às festas populares e ao folclore brasileiro, diferem substancialmente dos demais por terem como principal característica a compilação de textos de outros autores como elemento catalisador da narrativa, e menos o relato da viagem em si.

Chama atenção o título da obra, que não indica a palavra viagem, relato ou excursão, como costumeiramente faziam outros viajantes. Além disso, em italiano é mais usual Madonna para se referir à Virgem Maria, e Nostra Signora, italianização da forma portuguesa Nossa Senhora, de acordo com Santos, parece ter a intenção de chamar a atenção para o exótico, o diferente. O Mar Doce refere-se ao nome já dado às terras do Amazonas e do Pará, o que indica a alusão da autora a viajantes anteriores, e o subtítulo, Missioni e Paesaggi di Amazzonia, pode referenciar dois elementos de destaque na narrativa:

as missões, que podem ser vistas tanto como uma referência às atividades dos padres capuchinhos visitadas durante a viagem, como à missão econômica dos empreendedores italianos, e às paisagens, lugar comum dos viajantes, principalmente para aqueles que visitaram as regiões tropicais. (Santos, 127).

Como se percebe, já o título traz em si mais de uma possibilidade de interpretação da obra, de modo que, retomando a tese 
de Santos, Nostra Signora del Mar Dolce não é um simples relato de viagem, pois

o gênero 'narrativa de viagem' não é somente um apanhado de memórias de viagem ou longos tratados científico-etnográficos, mas sim, uma construção individual que se dá no âmbito da memória, e que é assentado por determinados objetivos. (172)

Nessa perspectiva, ainda segundo Santos (2014), podemos ler o relato de Ferruggia a partir da articulação de três níveis de narrativa, ou três viagens, que se alternam e se inter-relacionam: a primeira é a viagem literal, marcada pela saída do vapor Re Umberto do porto de Gênova em 10 de setembro de 1898 e a chegada em Belém do Pará no final daquele mês. A viagem foi feita em companhia do seu marido, Agostino Luigi Tettamanzi, jornalista conhecido pelo pseudônimo de Alberto Manzi, e é possível que tenha sido patrocinada pelo governo italiano, interessado em saber como viviam os emigrantes italianos em terras brasileiras. A atuação de Ferruggia na causa imigratória está expressa principalmente nos artigos de jornais, nos quais defende que o governo italiano apoie os italianos residentes no exterior, pois, a despeito do incentivo do Governo brasileiro para a vinda dos italianos ao Brasil a partir de 1870, pouco tempo depois as notícias sobre as más condições em que viviam e trabalhavam os emigrantes em solo brasileiro passaram a ser frequentes nos jornais e nos círculos políticos e intelectuais italianos.

Vale lembrar que até o final do século XIX o número de viajantes italianos foi pouco expressivo no Brasil se comparado aos viajantes de outras nacionalidades. Após a Unificação Italiana, ocorrida em 1861, esse número passa a aumentar e muitos dos que se deslocaram o fizeram movidos por ambições políticas na disputa colonial que tinha como vetores a França e a Inglaterra, embora a literatura de viagem produzida pelos italianos não se compare à daqueles dois 
países (Scriboni, 306, apud Santos, 96). Há de se notar também o surgimento da Società Geografica Italiana, em 1867, e o consequente favorecimento de viagens com finalidades políticas, exploratórias e científicas, bem como de seu financiamento. É o caso, por exemplo, das viagens de personalidades como Giuseppe Raddi, Ernano Stradelli e Luigi Buscalioni, que ao longo do século XIX estiveram no Brasil e deixaram contribuições, descritas de modo científico e ou estético, a respeito da fauna e da flora, dos minerais e do sistema hidro-geológico, dos habitantes e de suas lendas e costumes.

Ainda que o motivo da viagem de Ferruggia fosse o de acompanhar o marido, e mesmo estando interessada nas questões de imigração que seriam tratadas por ele, Ferruggia coloca-se também como alguém que busca a "poesia do lugar" (18), as particularidades das regiões visitadas. A falta de referências cronológicas no relato, que serviriam para mostrar o percurso do casal, podem ser um indício de que, para Ferruggia, menos importante eram os fatos em si e mais as impressões que a paisagem e o encontro com as pessoas provocavam. Daí porque, ainda segundo Santos, podemos pensar em uma segunda viagem de Ferruggia, a viagem literária, assim chamada porque, através da memória, sentimentos e emoções - logo, uma experiência mais subjetiva -, a autora faz surgir ou outro nível de narrativa, a elaboração pessoal e criativa, muitas vezes até idílica, em contraste com a viagem literal, em que o estranhamento e a falta de conforto são constantes. (169) A descrição do Círio de Belém, encontrada no capítulo aqui traduzido, pode servir como exemplo desse aspecto da narrativa:

Aquela procissão! Eu a vi passar, e fiquei imóvel, em pé, sem fôlego, na pequena varanda do Hotel Coelho [...] Cada vez que meu pensamento se volta para o espetáculo - único na memória pela originalidade, pelo contraste de luz, sombra, grandeza, miséria - experimento o mesmo sentimento de espanto e torpor, a mesma apaixonada sensação de admiração, de piedade, que senti enquanto a pessoa estava parada ao mesmo tempo em que a alma estava em frenesi. E 
como um tremor desconhecido até aquela hora, não encontrei outro assim em nenhum outro espetáculo ligado àquela hora, combinado com aquele sol que incendiava o ar, com aquele difuso som de sino, enquanto as pessoas desfilavam, desfilavam, desfilavam; gente branca, gente negra, gente de cor morena, bronzeada, dourada, amarela, variada e lenta, lenta e interminável; multidão inspirada e multidão cega, grandiosa em sua dupla manifestação de amor religioso e ingênua bestialidade! ${ }^{5}(213-214)$

A terceira viagem é chamada por Santos de viagem cultural, ou seja, um percurso pelas obras que a autora cita, muitas vezes fazendo uso de longos recortes, com o intuito de explicar o país visitado. Fazem parte desse conjunto relatos de viajantes como Stradelli e Coudreau, romancistas como Charles Nodier e José de Alencar, poetas como Baudelaire, além de histórias de santos, narrativas indígenas e africanas, relatos de religiosos, tratados científicos, histórias literárias que, em amálgama com a experiência da memória, servem para moldar a imaginação e ressaltar, ao público italiano, a imagem da região e do país como um lugar exótico, repleto de dificuldades, perigos e estranhezas, às quais estavam particularmente submetidos os conterrâneos imigrantes. (170-171) Ao que parece, Ferruggia acreditava que, se junto com descrições detalhadas e análises pessoais o leitor pudesse também contar com obras supos-

${ }^{5}$ Quella processione! Io l'ho vista passare, rimanendomene immobile, in piedi, senza respiro, nel terrazzino dell'Hôtel Coelho [...]. Ogni volta che ilpensiero ricorre allo spettacolo - unico nella memoria per originalità, per contrasto di luce di ombra, di grandezza, di miseria - provo la stessa sensazione di sgomento e di stupore: lo stesso appassionato sentimento di ammirazione, di pietà provato allora, mentre la persona sostava, immobile, mentre 1'anima era tutta in un fremito. E quale fremito ignoto sino a quell'ora non ritrovato più per nessun altro spettacolo legato a quell'ora, congiunto a quel sole che incendiava l'aria, a quel diffuso suono di campana mentre la gente sfilava, sfilava, sfilava; gente bianca, gente nera, gente di color morato, bronzino, dorato, giallo, varia e lenta, lenta e interminabile; folla ispirata e folla cieca, grandiosa nella sua doppia manifestazione di amor religioso e di ingenua bestialità! 
tamente familiares, essas referências poderiam auxiliá-lo a reconstruir as situações e sensações por ela vivenciadas. É o caso, por exemplo, da narrativa do Tamandaré, o pajé que repovoou a terra depois de uma grande inundação, lenda essa extraída d' $O$ guarani de José de Alencar e que, pode-se presumir, já estava presente no imaginário do seu público dado o sucesso da versão operística d' $O$ Guarani, de 1870, nos círculos italianos. Ferruggia assume, assim, o papel de narrador-guia, consciente das suas escolhas e ações, oferecendo a sua versão da viagem, escolhendo o que narrar, o que destacar, o que excluir.

Como foi dito, o capítulo traduzido para figurar nesse número especial de Cadernos de Tradução é Madonna Fantasia, no qual a autora trata dos rituais e festas religiosas do catolicismo, bem como aborda lendas e mitos das cosmogonias indígena e africana. Ferruggia faz uso de uma citação de Charles Nodier (1780-1844) sobre a fantasia, retirada do romance La Fée aux miettes, para iniciar a sua apresentação e contrapor o que ela chama de "fantasias delicadas", típicas dos países frios da Europa, e a fantasia, ou imaginação, característica dos países quentes, onde

Tudo arde, tudo queima, tudo acaba em um explosivo incêndio de passionalidade material. Por isso, festas religiosas, cerimônias sagradas, ritos de piedade, têm caráter profano, e estão tão ligadas a invenções de exagerada humanidade, que eu quis fundir sua descrição com as lendas. ${ }^{6}(171)$

Explica assim as razões por ter descrito e mesclado, no mesmo capítulo, festas populares e do cristianismo com mitos e celebrações indígenas e africanas. Descreve festas e rituais como os do Dabucuri, do Sairé, do Lundú, da máscara de Jurupari, festivida-

${ }^{6}$ Tutto arde, tutto abbrucia, tutto termina in un divampante incendio di passionalità materiale: per questo, feste religiose, sacre cerimonie, funzioni di pietà, hanno tal carattere profano, e sono così allacciate a invenzioni di morbosa umanità, che io ho voluto fonderne la descrizione con le leggende.

Cad. Trad., Florianópolis, v. 41, $\mathbf{n}^{0}$ esp. 1, p. 273-287, jan/jul, 2021. 
des em honra a São Bento, Nossa Senhora e Santo Antônio, dentre outros; evidencia a lenda de Jurupari e da Cobra Grande, e dá ênfase à procissão do Círio de Belém, sempre destacando o sincretismo religioso e recorrendo, de modo explícito, à autoridades que já haviam escrito sobre o assunto, o que, mais uma vez, leva a crer que seus relatos são o resultado não só das observações de viagem, como também de fontes bibliográficas e leituras que realizou.

Aspecto importante também presente neste capítulo é a forma como Ferruggia considera a composição do povo brasileiro e, de modo especial, das mulheres em seu papel social. A mulher é descrita primeiramente por sua condição étnica e hierarquizada:

Os diversos tipos femininos do lugar aparecem, nesta ocasião [a procissão do Círio], como marcados por sua beleza particular: a sedutora mulata, a preguiçosíssima negra, a interessante índia, a brasileira pequena e doce. ${ }^{7}(215-216)$.

Esta, de fato, é apresentada (e admirada) como uma mulher resignada e subserviente ao marido, dentro do espaço doméstico, como no caso de sua hospedeira Castorina, "uma mulher que personificava as melhores qualidades do seu país, de uma afetividade profunda, generosidade instintiva [...] falava pouco, sorria sutilmente, e enquanto os lábios se fechavam um pouco, os olhos se ofuscavam de tristeza." 8 (102)

Já as mulatas, vistas sob a lente centrada nas diferenças físicas, são descritas como inspiração para as canções populares, ligadas à dança e que exalam sedução, como nas barracas da festa do Círio, em que "A negra tirará a sorte, fará as invocações e o feitiço. A bela

\footnotetext{
${ }^{7}$ i diversi tipi femminili del paese appaiono, in tale occasione, come improntati a una particolare loro bellezza: la seducente mulatta, la pigrissima negra, la interessante indiana, la brasiliana piccola e dolce.

${ }^{8}$ una donna che personificava le migliori qualità del suo paese: di un'affettività profonda, di una generosità istintiva [...] parlava poco, sorrideva appena, e mentre le labbra si schiudevano un poco, gli occhi si offuscavano di tristeza.
} 
morena irá mostrar suas toilettes de cor branca ou rosa, mostrando um perfeito decolleté na hora de preparar o haxixe, a ser oferecido fresco aos degustadores."9 (212). As negras, por sua vez, são vistas ora como substitutas das ciganas curandeiras e adivinhas, incapazes de saírem do estado da inércia e da preguiça, enquanto à mulata, já detentora do "sangue branco" nas veias, símbolo da mistura das raças, caberia a tarefa de criar uma nova raça:

Felizmente, o negro não tem nada mais contra ele a não ser alguns preconceitos, pelos quais vive um pouco à margem, mas estamos longe dos tempos em que o Papa foi obrigado a publicar uma bula especial para declarar válido, e não pecaminoso, o casamento de um branco com uma negra, e viceversa. [...] A mulata, fruto do droit du seigneur, passou a ser admirada e amada, produzindo aquela mistura de sangue que daria origem a uma nova raça ${ }^{10}$. (Ferruggia, 181)

Ferruggia mostra ignorar, ou omitir, os resquícios da violência escravocrata e patriarcal no Brasil, e a maioria das suas análises, bastante generalistas e marcadas por estereótipos, não são muito diferentes das visões de outros viajantes e do pensamento cientificista e positivista do final do século XIX que defendia o conceito de superioridade racial - pode-se lembrar, a esse respeito, a boa aceitação das teorias de antropologia criminal de Cesare Lombroso, em voga na mesma época, e sua relação com o expansionismo nacio-

\footnotetext{
${ }^{9}$ La negra dirà buona ventura: farà gli scongiuri, e il feitiço. La bella mora sfoggierà le sue toilettes bianche, o color di rosa, mostrando un perfetto decolleté, nel preparare l' hassay, da offrire fresco ai degustatori.

${ }^{10}$ Per fortuna, il negro non ha più contro di sè che alcuni pregiudizii, per i quali vive un po' in disparte: ma siamo ben lontani dai tempi in cui il Papa era costretto a pubblicare una bolla apposita per dichiarare valido, e non peccaminoso, il matrimonio di un bianco con una negra, e viceversa. [...] La mulatta, fruto del droit du seigneur, è venuta a farsi ammirare ed amare, producendo quel miscuglio di sangue che doveva dar origine a una nuova razza.
} 
nalista e as justificativas para as desigualdades sociais. A narrativa de Ferruggia, portanto, se por um lado é hoje passível de muitas críticas, por outro, deve ser vista como depositária das referências culturais do seu tempo, que nutrem uma espécie de jogo ambíguo onde o estranhamento em relação ao outro pode comportar rejeição, admiração, exotização, desconhecimento. Buscar compreender esse conjunto simbólico manifesto nas diferentes linguagens que compõem os relatos de viagem, identificar as conexões entre os vários níveis da narrativa, articular as experiências individuais com outras mais amplas torna-se, assim, o primeiro exercício para empreender a prática da tradução, para a qual, segundo Paulo Rónai, o tradutor deve manter-se atento à "lei psicológica da linguagem" (16), ou seja, à dinâmica inseparável entre o pensamento e sua forma de expressão, e, ao mesmo tempo, "contentar-se com aproximações" (25), já que não há como captar o sentido absoluto das palavras, o tom exato, as intenções ocultas de quem escreve. A tradução foi realizada com base nessas premissas e, a seguir, apresento algumas considerações pontuais acerca do processo.

Mantive a maioria dos sinais gráficos presentes na edição de partida, por considerar que estes fazem parte da materialidade do texto e porque provavelmente a autora tinha o objetivo de utilizá -los como forma de chamar a atenção do público leitor. O leitor e a leitora notarão que Ferruggia utiliza-se da ferramenta itálico em pelo menos cinco momentos: 1. para identificar palavras como $\mathrm{ca}$ chaça, caxiri, caruatá, lundu, canoa, congo, pajé, taxaua, saúva, beijú, cuja tradução não seria possível em italiano, e por isso foram marcadas em itálico no texto italiano, como estrangeirismos; 2. palavras como sítio, juiz, juíza, festeiros, mordomos, avenida, que, embora não apresentem grandes desafios de tradução ao italiano, foram mantidos em português no texto italiano, possivelmente para proporcionar ao seu público um contato mais próximo com a língua e a cultura sobre a qual estava escrevendo, ou talvez por acreditar na "intraduzibilidade" da língua; 3. palavras e expressões como proposta, riservatezza, altre malattia, rappresentati, que parecem indicar destaque ou certa ironia no texto; 4. palavras ou expres- 
sões estrangeiras, como droit du seigneur, chalêts, café-chantants, toilettes, decolleté, brick, buvette; 5. nomes próprios como Jurupary, Ceucy, Uarly, Jacy, Curupira, Caapora, Maty-Tapèrê que, porém, tiveram sua ortografia atualizada para Jurupari, Ceuci, Jaci, Caipora, Matim-Taperê. A mesma atualização gráfica deu-se na tradução de palavras como yaras, tucuman, Cyrio, que se tornaram iaras, tucumã, Círio. Se os itálicos foram mantidos, outros sinais gráficos presentes na edição foram excluídos, por não serem usuais no português brasileiro, como o uso de aspas no início de todas as linhas de citações.

Em relação à pontuação, procurei observar e manter o ritmo dado pelo texto de partida, embora algumas modificações tenham sido feitas para não comprometer a legibilidade do texto. O uso de travessões é bastante perceptível no texto de Ferruggia, mas no texto em português foi suprimido algumas vezes, quando entendeu-se que seu uso se destinava mais a marcar uma pausa do que um maior destaque. Para marcar o ritmo do texto, o travessão foi substituído por vírgula ou ponto final. O mesmo se deu em relação ao uso dos dois pontos, que em vários momentos foram usados mais de uma vez na mesma frase, ou em situações que normalmente não seriam usadas em português. Neste caso, foram substituídos por vírgula ou ponto final, por terem sido utilizados com a finalidade de dar uma sequência ao desencadeamento das ideias, o que na tradução foi feita com vírgula e ponto final, como no exemplo:

- Tu sarai il cujubin (Penelope cumanensis: ha le piume rosee e la testa bianca: canta allo spuntar del giorno). Così fece il cujubin: ne dipinse la testa in bianco con argilla: le gambe in rosso con del roucou (Bixa orellana) e gli disse: (197)

assim traduzido:

- Você será o cujubim (Penelope cumanensis, com penas rosadas e cabeça branca, canta ao amanhecer). Assim ela 
fez o cujubim: pintou a cabeça de branco com argila, as pernas de vermelho com urucum (Bixa orellana). E disse-lhe:

Por fim, Ferruggia faz uso de reticências que também parecem marcar o ritmo do tempo, ou ainda do próprio pensamento da autora no momento de retomar suas memórias e escrevê-las no texto, promovendo pausas e reflexões. Nesse sentido, esse tipo de pontuação foi predominantemente mantido. Importante dizer que a pontuação é uma das ferramentas para a construção da sintaxe do texto, então o projeto e a elaboração da tradução procurou observar e manter essas características da obra, assim como a colocação das palavras na frase, em especial sobre o uso de adjetivos antepostos ao nome, como em "profumate e primitive scodelle" (174) [perfumadas e primitivas tigelas] "celeste bellezza" (183) [celestial beldade], "roventi parole" (191) [ferventes palavras]. Para concluir, notas explicativas foram usadas quando entendeu-se que a compreensão do leitor e da leitora pudesse ficar comprometida pela ausência de informações disponíveis.

\section{Referências}

Ferruggia, Gemma. "Madonna Fantasia". Nostra Signora del Mar Dolce. Missioni e paesaggi di Amazzonia. Milano: Tipografia Editrice L.F. Cogliati, 1902. pp. 170-236.

Ferruggia, Gemma. Nostra Signora del Mar Dolce. Missioni e paesaggi di Amazzonia. Milano: Tipografia Editrice L.F. Cogliati, 1902. https://archive.org/ details/nostrasignorade00ferrgoog/page/n7/mode/2up. Acesso em 12 janeiro 2021.

Lea Pacella, Marzia. Gemma Ferruggia. Dizionario Biografico degli Italiani. v. 47. Roma: Treccani, 1997. https://www.treccani.it/enciclopedia/gemmaferruggia_(Dizionario-Biografico)/. Acesso em 08 de janeiro de 2021.

Cad. Trad., Florianópolis, v. 41, $\mathrm{n}^{0}$ esp. 1, p. 273-287, jan/jul, 2021.286 
Ronai, Paulo. Escola de tradutores. $7^{\mathrm{a}}$ ed. Rio de Janeiro: José Olympio, 2012.

Santos, César Palma dos. Nostra Signora del Mar Dolce: a (re) criação da viagem na narrativa de Gemma Ferruggia. 2014. 200 f. Tese (doutorado) - Universidade Estadual Paulista "Julio de Mesquita Filho", Faculdade de Filosofia, Ciências e Letras de Assis, 2014. http://hdl.handle.net/11449/115631. Acesso em 10 de janeiro de 2021.

Vangelista, Chiara. "Una viaggiatrice italiana di fine Ottocento: Gemma Ferruggia in Amazzonia". Revista de História e Estudos Culturais, v. 13 Ano XIII n ${ }^{\circ} 1$ Janeiro-Junho 2016. http://www.revistafenix.pro.br/vol37-a03.php. Acesso em 17 de dezembro de 2020.

Karine Simoni. E-mail: kasimoni@gmail.com. https://orcid.org/0000-00034965-7196.

Cad. Trad., Florianópolis, v. 41, $\mathrm{n}^{0}$ esp. 1, p. 273-287, jan/jul, 2021.287 